\title{
Derechos humanos y justicia con las personas con diversidad funcional
}

\author{
Human rights and justice to people with functional diversity \\ MANUEL APARICIO PAYÁ \\ ies Aljada, Puente Tocinos, Murcia
}

Artículo recibido: 03 marzo 2016

Solicitud de revisión: 08 marzo 2016

Artículo aceptado: 16 abril 2016

\section{Resumen}

Uno de los problemas de justicia más importantes que existen en la actualidad es el que se refiere a los seres humanos con diversidad funcional. Desde hace algunas décadas el modelo social de la discapacidad ha insistido en que estos deben ser contemplados como sujetos activos de justicia y no como meros sujetos pasivos de beneficencia. La pretensión de este artículo es doble: por un lado, aplicando la teoría de la justicia como reconocimiento de A. Honneth, indagamos en qué consiste dicho trato justo; por otro lado, siguiendo la ética cordial de Cortina, abordamos la cuestión del fundamento de los derechos de las personas con discapacidad.

Palabras clave: Diversidad funcional, modelo social de la discapacidad, reconocimiento, dignidad, derechos humanos.

\begin{abstract}
One of the most important problems of justice existing today is centred on human beings with functional diversity. Through the last few decades the social model of disability has insisted on the fact that these individuals should be considered active subjects of justice and not only mere passive subjects of charity. The aim of this article is twofold: on the one hand, applying the theory of justice as recognition by Honneth, we investigate what such fair treatment consists of; on the other hand, following the cordial ethics by Cortina, we deal with the question of the basis of the Rights of People with Dissabilities.
\end{abstract}

Keywords: functional diversity, social model of disability, recognition, dignity, Human Rights. 


\section{INTRODUCCIÓN}

Este año se celebra el $x$ aniversario de la aprobación por la onu de la Convención internacional sobre los derechos de las personas con discapacidad. Su aprobación el 13 de diciembre de 2006 fue el resultado de un largo proceso en el que, además de los estados miembros y de instituciones dedicadas a los derechos humanos, colaboraron estrechamente un amplio número de organizaciones de personas con diversidad funcional ${ }^{1}$ y sus familias. Este primer documento moral-jurídico de derechos humanos del siglo xxi marca el inicio de la conciencia mundial acerca de la situación problemática vivida por la inmensa mayoría de los seres humanos que tienen algún tipo de diversidad en su funcionamiento corporal. ${ }^{2}$ Puede decirse que en sus páginas late una nueva visión de las personas con diversidad funcional. Frente a la tradicional imagen social que las considera como meras receptoras pasivas, al tener en cuenta, exclusivamente, las diversas necesidades atípicas que presentan, ahora se las concibe también como sujetos activos de justicia, ${ }^{3}$ a los cuales les debe ser reconocida su

1 La discusión teórica sobre la conveniencia de usar el término diversidad funcional, en lugar del término discapacidad, sobrepasa las posibilidades de este artículo. Tal discusión puede verse en Canimas (2015), quien acepta el término diversidad funcional, aunque se muestra crítico con el modelo de la diversidad. También pueden verse las tensiones generadas por el modelo de la diversidad funcional en Etxeberría (2008: 45). En todo caso, empleamos el término diversidad funcional por dos razones: 1) valoramos que este concepto recoge la idea, subrayada desde el «modelo social», de que una cosa es el funcionamiento diverso de las personas y otra distinta es que sea la interacción de la persona con diversidad funcional con una sociedad injusta la causante de la discapacidad y 2) se trata de un término cada vez más empleado en la literatura científica en España, introducido desde el modelo de la diversidad funcional, formulado por A. Palacios y J. Romañach. Aunque utilizamos este nuevo término, defendemos una concepción universalista que hace descansar la justicia en la dignidad de la persona. Un universalismo - en consonancia con lo sostenido por Honneth - que no es ciego a la diferencia, sino que la acoge y la trata con referencia al principio de igualdad. Dicho trato moral-jurídico protege a cualquier ser humano de la vulnerabilidad física (también de la vulnerabilidad social) a que está expuesto, en tanto que somos seres que tenemos y «somos cuerpo». Nuestro planteamiento puede encuadrarse en el modelo de los derechos (Seoane, 2011).

2 Usamos el término "corporal» en un sentido amplio, no opuesto a «mente», adoptando un monismo emergentista -defendido, entre otros, por Laín-Entralgo y, en el campo neurocientífico, por A. Damasio-: lo corporal -que incluye al cerebro- permite la aparición de la mente y de la conciencia. Sin caer en un reduccionismo, entendemos que la diversidad funcional mental o la diversidad funcional intelectual -que presentan características distintas a la diversidad funcional física- pueden incluirse también bajo la categoría de "diversidad funcional corporal», al menos en la medida en que existen bases orgánicas de las mismas. No obstante, en el caso de las personas con diversidad funcional intelectual o mental, existen matices diferenciales respecto a la puesta en práctica de la condición de ciudadanía. A pesar de las dificultades prácticas de realización de algunos derechos en tales personas, el conjunto de la Convención -como bien señala Etxeberría- constituye un horizonte insoslayable hacia el que dirigirse.

3 Así, por ejemplo, en el Preámbulo de la Convención, apartado 0, se señala expresamente que se considera que las personas con diversidad funcional «deben tener la oportunidad de participar 
autonomía y el conjunto de sus derechos humanos. Esta nueva imagen social de las personas con diversidad funcional se ha ido tejiendo desde las últimas décadas del siglo xx hasta la actualidad, impulsada desde el plano teórico por el modelo social de la discapacidad y por las luchas por el reconocimiento -quizás más difusas y silenciosas- que, alimentadas por dicho marco teórico, se han llevado a cabo por las propias personas con diversidad funcional y por quienes les apoyan. En ese sentido, se ha señalado que la Convención de 2006 responde a una clara y decisiva influencia del modelo social (Palacios, 2008), cuyo principal activo ha sido el haber situado la cuestión de la discapacidad en el ámbito de la justicia y de los derechos humanos. Este documento moral-jurídico internacional tiene un doble sentido normativo (Palacios, 2008): proteger contra la discriminación sufrida por las personas con diversidad funcional y aportar herramientas para que gocen y ejerzan sus derechos. Responde, pues, al principio de igualdad, por lo que orienta normativamente a que cada persona pueda lograr, en igualdad de condiciones con respecto a cualquier otra, el desarrollo más pleno posible de su plan de vida. Una vida reconocida como igualmente digna y valiosa.

En este artículo hacemos una breve presentación de los presupuestos básicos del modelo social de la discapacidad, en tanto que origen de la transformación de la imagen social de las personas con diversidad funcional. Posteriormente realizamos un análisis del sentido normativo de los derechos establecidos en la Convención de 2006, tomando como referencia la teoría de la justicia como reconocimiento de Honneth. Finalizamos el trabajo recurriendo a la ética cordial de Cortina, con el fin de encontrar un fundamento que justifique los derechos humanos recogidos en el citado documento moral-jurídico internacional.

\section{LA APELACIÓN A LA JUSTICIA Y LOS DERECHOS HUMANOS DESDE EL MODELO SOCIAL DE LA DISCAPACIDAD}

El denominado modelo social de la discapacidad (Barton, 1998; Palacios, 2008) surge en los últimos decenios del siglo $\mathrm{xx}$, influido por las luchas sociales iniciadas en la década de los 60 del pasado siglo, fundamentalmente en EeuU, por los movimientos de defensa de los derechos civiles.

activamente en los procesos de adopción de decisiones sobre políticas y programas, incluidos los que les afectan directamente». 
Bajo el impulso de las ideas de libertad y autonomía, surgieron en aquel momento una serie de movimientos sociales de liberación -de las mujeres, de las personas negras, de los pacientes, etc. En ese contexto surgió (Palacios, 2008) el Movimiento de Vida Independiente, iniciado por Ed Roberts, estudiante con discapacidad severa que luchaba para poder ingresar en la Universidad de Berkeley (California). Este movimiento social se basa en la ayuda mutua y en la auto-organización del grupo de personas con discapacidad. En el año 1972 se creó en Estados Unidos el primer Centro de Vida Independiente -alternativo a la institucionalización- dirigido por personas con diversidad funcional y basado en el objetivo de inclusión social. En 1978 estos centros recibieron ayuda financiera del Congreso norteamericano, lo que ayudó a su expansión por todo el país, fomentando la filosofía de los derechos civiles de las personas con discapacidad. Este movimiento fue extendiéndose por otros países, especialmente en Suecia, Canadá, Inglaterra, llegando a España en el año 2001 (Palacios y Romañach, 2006). En Inglaterra, en el año 1976, la Unión de Personas con Deficiencias Físicas contra la Segregación (Union of Physically Impaired Against Segregation, UPIAs), propuso los llamados principios fundamentales de la discapacidad, más tarde recogidos por Mike Oliver con la denominación de modelo social. Un paso importante para este modelo lo constituye la fundación de la revista Disability, Handicap and Society, publicada por primera vez en 1986. Dicha revista aglutinó una serie de importantes trabajos de sociología crítica de la discapacidad en el ámbito anglosajón.

En el terreno legislativo, cabría citar la promulgación en Estados Unidos de la Ley de Americanos con Discapacidad -American With Disability Act 1990-, en la que tuvo gran influencia el Movimiento de Vida Independiente. Los cambios en la percepción social de las personas con discapacidad favorecieron la promulgación en numerosos países de Europa y en otros países del mundo, durante la década de los 90, de legislaciones antidiscriminatorias, al tiempo que se impulsaba la protección social de la dependencia. En ese marco legislativo, se promulgó recientemente en España la Ley de Dependencia, Promoción de la Autonomía personal y Atención a Personas en Situación de Dependencia. Finalmente, en el ámbito del derecho internacional se promulgó la Convención de 2006.

En lo que se refiere a su origen teórico, el modelo social comienza con los trabajos de la sociología crítica de la discapacidad, desarrollados en Inglaterra a partir de la década de los 80 del pasado siglo. Se trata de un nuevo paradigma producido por la confluencia de varias corrientes de 
pensamiento: las teorías materialistas (Finkelstein, Oliver, Abberley), la teoría feminista (Jenny Morris) y diversos autores encuadrados en las corrientes post-modernas. Frente a los planteamientos sociológicos positivistas e interpretativos, la sociología crítica de la discapacidad pretende, en primer lugar, realizar sus investigaciones incorporando de forma activa la voz de las personas con diversidad funcional. En segundo lugar, considera que la orientación de la investigación no tiene que centrarse en el análisis de las personas con diversidad funcional sino en la sociedad discapacitante, en las estructuras sociales que originan y mantienen la opresión. Más allá de los factores experienciales, propone atender a factores estructurales -situación económica, empleo, condiciones arquitectónicas, circunstancias familiares, etc.- cambiantes en el tiempo. Por ello, la discapacidad no puede ser contemplada como un estado estático, sino como algo temporal y cambiante. Por último, entiende que el objetivo de la investigación sociológica es la consecución de la emancipación de las personas con diversidad funcional mediante la transformación social:

La idea integradora que atraviesa el modelo de pensamiento social y la investigación emancipadora en discapacidad es su propósito transformador; es decir, la supresión de barreras y la promoción de la autosuficiencia tanto individual como colectiva de las personas con discapacidades. Desde este punto de vista, la función del investigador es ayudar a facilitar la concreción de estos objetivos mediante el proceso de investigación (Barnes, 2008: 384).

El modelo social es, en suma, un modelo sociopolítico que pretende superar la concepción naturalista de la discapacidad defendida por el modelo médico, surgido desde el pensamiento científico a partir del siglo XVII. El punto nuclear de este nuevo modelo es la distinción entre «discapacidad» $\mathrm{y}$ «diversidad funcional». Por diversidad funcional se entiende la carencia parcial o total de un miembro, o la posesión de un miembro, órgano o mecanismo del cuerpo que tiene un funcionamiento diferente. Es, pues, un concepto referido al plano corporal del individuo. Por el contrario, el modelo social concibe la discapacidad en un plano diferente: como el conjunto de desventajas o limitaciones de la actividad que tienen su origen en el modo de estar organizada la sociedad, cuando se margina o excluye a las personas con diversidad funcional. En suma, el modelo social remarca que la discapacidad no es un fenómeno patológico natural, tal y como se apuntaba desde el modelo médico. Dando ahora un giro de ciento ochenta grados, este nuevo modelo la interpreta como una patología social, considerándola como una forma de opresión (Abberley, 2008) a la que se somete a las personas cuyos cuerpos funcionan de modo diferente al esta- 
dísticamente habitual. Las causas que provocan la discapacidad no pueden ser concebidas como causas naturales, ya que pertenecen al orden social. El entorno social, construido por personas sin diversidad funcional utilizando sus propias normas, discrimina o excluye a los grupos de personas con diversidad funcional, lo que hace emerger la discapacidad. Son las barreras -económicas, sociales, políticas o culturales- que la sociedad ha ido construyendo, por acción u omisión, las que discapacitan a los individuos con diversidad funcional. En consecuencia, las medidas propuestas para el cambio social han de ir dirigidas al conjunto de la sociedad y no a la rehabilitación corporal.

El modelo social introduce, pues, un auténtico giro copernicano en el tratamiento del tema. Al concebir la discapacidad como una categoría social y política, convierte en cuestiones significativas la justicia, la igualdad, la ciudadanía y los derechos humanos de las personas con diversidad funcional. Ese haber del modelo, no obstante, no debe ocultar el debe de su reduccionismo social, ya que olvida la cuestión del cuerpo y la vulnerabilidad (MacIntyre, 2001; Nussbaum, 2007). Desde nuestro punto de vista, el rescate de esta cuestión no tiene que suponer una vuelta al reduccionismo propio del modelo médico.

\section{APLICACIÓN DEL ENFOQUE DEL RECONOCIMIENTO DE HONNETH AL ÁMBITO DE LA DIVERSIDAD FUNCIONAL}

La teoría de la justicia de Axel Honneth constituye un valioso enfoque diagnóstico-evaluativo de la justicia (Forst, 2014). Dicho marco teórico, centrado en la noción de reconocimiento, constituye un instrumento útil para desentrañar una variedad de experiencias sociales de injusticia (Fraser y Honneth, 2006). Su planteamiento teórico indaga en las bases morales que tienen los conflictos sociales en los que hay demandas de justicia, mostrando que la calidad moral de las relaciones sociales va más allá del establecimiento de principios generales de justicia distributiva. Honneth considera que la identidad personal se construye de forma intersubjetiva, en interacción con el medio social. Lo cual implica que la falta de un adecuado reconocimiento social, sufrido por personas pertenecientes a grupos marginados o excluidos -como ocurre con las personas con diversidad funcional-, sumerge a la persona en una experiencia de injusticia. Esta se traduce en un daño moral a la dignidad de quien la sufre, poniendo en peligro también la identidad personal. Con su teoría de la justicia como 
reconocimiento, Honneth muestra la necesidad de salvaguardar la igual consideración de toda persona, para la cual se necesita del adecuado reconocimiento mutuo, en su triple dimensión afectiva, jurídica y simbólicocultural.

A nuestro juicio el enfoque del reconocimiento propuesto por Honneth resulta relevante para abordar la cuestión de la justicia con las personas con diversidad funcional ya que su concepto de lucha por el reconocimiento ilumina las demandas de justicia producidas en las últimas décadas por tales personas y quienes les apoyan. Por otra parte, su marco teórico permite disponer de un criterio normativo que muestra formas diferenciadas de menosprecio moral dadas en las relaciones intersubjetivas, al tiempo que permite encuadrar, de forma entrelazada, reivindicaciones justas realizadas por tales grupos de personas: la construcción de una identidad intacta, la inclusión social igualitaria, las mejoras materiales y la problemática de la valoración social positiva.

El enfoque del reconocimiento, formulado por Honneth, parte de la atención a diferentes formas negativas de relación intersubjetiva: el menosprecio a la integridad corporal, el menosprecio a los derechos y el menosprecio al valor del modo de vida propio. En todas estas formas de menosprecio se encuentra una falla en el reconocimiento que debe producirse en la relación intersubjetiva, con el fin de poder construir una identidad no dañada, respetar la dignidad personal y alcanzar la autorrealización.A partir de este acercamiento a las formas variadas de injusticia indaga en las diferentes esferas normativas de reconocimiento: el reconocimiento afectivo, el reconocimiento jurídico y moral y el reconocimiento solidario (Honneth, 1997). Una vez identificados los tipos de reconocimiento emergentes en la sociedad burguesa-capitalista, esboza Honneth una teoría tripolar de la justicia (Fraser y Honneth, 2006). Concibe los principios de la justicia -principio de necesidad, principio de igualdad jurídica y principio de mérito- como principios ético-políticos de reconocimiento. Por otra parte, remite estos principios a una igualdad situada en un nivel superior: debe darse un trato igual a todos los individuos, en el sentido de que todos los individuos merecen por igual el reconocimiento de su necesidad, de su igualdad jurídica y de su mérito, con vistas a la formación de su identidad y al logro de la autorrealización.

En este artículo nos centramos en uno de los aspectos de su concepción tripartita de la justicia: la igualdad jurídica que, según Honneth, tiene una cierta primacía en relación a las demás. En ese sentido, el menosprecio a los derechos humanos de las personas con diversidad funcional constitu- 
ye una falla en el reconocimiento que debe ser superada. El reconocimiento de los derechos humanos en el orden jurídico de cada sociedad constituye la otra cara de la moneda y resulta fundamental para construir una sociedad que trate con justicia a dichas personas.

\section{EL RECONOCIMIENTO DE LOS DERECHOS HUMANOS DE LAS PERSONAS CON DIVERSIDAD FUNCIONAL}

El derecho moderno recoge en su seno las luchas por el reconocimiento, iniciadas ante la variedad de experiencias de menosprecio (Honneth, 1997). Tales luchas siguen dos direcciones: a) la ampliación de los contenidos materiales -garantía de un mínimo de seguridad económica y de formación cultural-, que atiende a las diferencias existentes en las oportunidades individuales para la realización de las libertades garantizadas socialmente, de forma que se asegura jurídicamente la igualdad de oportunidades para que los individuos puedan participar en la formación pública de la voluntad y b) la universalización, mediante la cual se reconoce a un número creciente de grupos anteriormente excluidos o discriminados iguales derechos que a los demás miembros de la sociedad. El universalismo jurídico de las sociedades modernas, que incorpora una moral postconvencional, está basado en el principio de igualdad jurídica. La apelación a este principio impulsa las transformaciones del orden social, en la medida en que la tensión entre el principio normativo de igualdad jurídica y las desigualdades fácticas constituye la fuente de los conflictos sociales (Fraser y Honneth, 2006). El menosprecio a los derechos de los grupos discriminados o excluidos choca con el principio de que todos los ciudadanos son, desde el punto de vista jurídico, iguales. Tal desajuste entre lo normativo y lo fáctico motiva moralmente a estos grupos a iniciar una lucha por el reconocimiento que lleva a la ampliación de la universalización jurídica. Esta dialéctica moral de lo universal y lo particular es lo que permite explicar, desde un plano normativo, el significado de las reivindicaciones históricas de igual ciudadanía producidas por parte de los diferentes movimientos de personas con diversidad funcional. A la luz del principio de igualdad jurídica vigente y de la exclusión experimentada por estos colectivos, debida a la interacción entre las diferencias corporales que presentan y una sociedad discapacitante, surgen las reivindicaciones morales para hacer frente a lo que los afectados -o sus familias- perciben como injusticias. Los avances sociales producidos desde los últimos decenios del siglo xx suponen que 
se deje de contemplar a las personas con diversidad funcional únicamente como personas que deben ser rehabilitadas y asistidas, pasando ahora a ser contempladas también como personas jurídicas, es decir, como ciudadanos que deben tener los mismos derechos que el resto de miembros de la comunidad. Esta lucha por el reconocimiento jurídico desemboca, a principios del siglo xxi, en el compromiso moral-jurídico plasmado en la Convención de 2006. Este documento jurídico obliga ${ }^{4}$ a los estados firmantes a promover, proteger y asegurar la igualdad de derechos de este colectivo. La expansión del reconocimiento de los derechos humanos -derechos civiles, políticos y sociales- hasta abarcar a las personas con diversidad funcional otorga a las mismas -cuando son implementados- el respeto social necesario para que puedan construir su autorrespeto, como forma positiva de referirse a sí mismas.

\subsection{El reconocimiento de los derechos civiles y políticos}

El valor ético de la autonomía individual, concebida como la capacidad del sujeto para la autodeterminación, constituye la piedra angular (Honneth, 2014) sobre la que se erige la modernidad. El derecho moderno encarna ese valor fundamental en un sentido universalista: todos los sujetos de derecho han de contar normativamente con igual autonomía individual para gobernar su vida. Honneth sigue a Habermas señalando que esta autonomía individual, en el progresivo desarrollo histórico del derecho, ha de ser entendida en un doble sentido: como autonomía privada y como autonomía pública.

El despliegue de la positivización de los derechos modernos comenzó con el establecimiento de los derechos liberales de libertad. Honneth concibe estos derechos como derechos negativos que protegen a la persona de intromisiones ilegítimas del Estado o de otras personas en su libertad, su vida o su propiedad, favoreciendo la construcción de sus propios objetivos de vida (Honneth, 2014). El disfrute de estos derechos, reflejados en normas positivas creadas y garantizadas coercitivamente por el estado, asegura a todos los ciudadanos, en cuanto que son sus destinatarios, igual protección de su autonomía privada. Posteriormente aparecerá un segundo tipo de derechos, los derechos políticos de participación, relacionados

4 Xabier Etxeberria propone, no obstante, una actitud de cautela ante este documento, ya que, en su opinión, es necesaria la vigilancia crítica de los responsables políticos y la participación activa de los ciudadanos para que se vaya pasando «del dicho al hecho» (Etxeberría, 2008: 11). 
con los procesos públicos de formación de la voluntad. En el marco del estado democrático, el otorgamiento de estos derechos convierte a los ciudadanos en autores del derecho. En el devenir histórico, el sistema jurídico hace posible el surgimiento de la autonomía pública, que permite a los sujetos cooperar mediante la deliberación para la formación de la voluntad jurídica. Ambos modos de concreción de la autonomía individual resultan complementarios.

Entendemos que en relación a la autonomía individual, dada la variedad de tipos de diversidad corporal existentes, hay que tener en cuenta lo siguiente:

a) El logro de la autonomía individual requiere de la acción conjunta de los diferentes tipos de derechos: la autonomía privada, hecha posible en sus condiciones materiales por los derechos sociales, exige la autonomía pública, de forma que «todos los afectados reciban la efectiva oportunidad de elevar su voz para reclamar sus propios derechos desde sus experiencias concretas de integridad vulnerada» (Habermas, 2008a: 511). Por eso, ha de ser la propia persona ${ }^{5}$ la que ha de poder determinar libremente -en lo posible- su plan de vida. Debe contar, para ello, con la apoyatura del conjunto de derechos y con la implementación subsiguiente de políticas públicas, dentro de mínimos decentes, para, cerrando el círculo, poder participar-de acuerdo a sus circunstancias- en la reclamación de sus derechos vulnerados. Cuando las circunstancias fácticas extremas no hagan esto posible, la autonomía privada y pública quedará en manos de los representantes, quienes deberán actuar en el legítimo interés del representado.

b) La persona está abierta a relaciones intersubjetivas, no sólo jurídicas, sino también de cuidado amoroso y de solidaridad, desde la que construye su plan de vida. Desde ese punto de vista, entendemos que no se debe contemplar la autonomía individual como una especie de isla. Es una autonomía tejida con las relaciones de reconocimiento desarrolladas en las redes sociales -familia, amigos, relaciones personales, instituciones, etc. Así, pues, no somos independientes sino que realmente somos in(ter)dependientes: en los contextos sociales,

5 En el artículo 19 de la Convención se reconoce el derecho de toda persona con diversidad funcional a vivir de forma independiente y estar incluido en la comunidad en igualdad de condiciones, sin que se vea obligada a vivir de acuerdo a un sistema de vida específico. Se reconoce el derecho a la asistencia personal y a disponer de servicios comunitarios que apoyen su plan de vida. 
cualquier persona cuenta con otras en apoyo de su plan de vida. También hay que considerar que cada persona tiene unos condicionantes internos, influidos a su vez por condiciones sociales. En ese sentido, una sociedad que reconozca los derechos de todos y que elimine o haga disminuir notablemente las barreras discapacitantes -incluyendo la discriminación- protegerá mejor la autonomía personal.

c) Hay que tener en cuenta la diferencia (Etxeberría, 2008) entre autonomía moral -de decisión racional- y autonomía fáctica -de ejecución. Para fomentar la autonomía fáctica es necesario rediseñar los espacios sociales, adoptando, progresiva y continuadamente, medidas políticas -eliminación de barreras arquitectónicas, promoción de dispositivos tecnológicos, asistencia personal, etc. Para fomentar la autonomía moral, hay que tener en cuenta que está también sujeta a condiciones y responsabilidades sociales -educación, socialización, etc.- para su realización, por lo que hay que verla desde una perspectiva diacrónica y con los apoyos sociales requeridos en cada momento de su desarrollo. Este apoyo social es necesario para la maduración, en el máximo grado posible, del más amplio espectro de capacidades racionales de la persona. También hay que tener en cuenta la gradualidad individual con que se presenta este tipo de autonomía en el caso de las personas con diversidad intelectual. Que una persona tenga limitaciones en la misma no significa que, por ello, haya de ignorarse lo que pueda decir. Debe atenderse a lo que la persona considera para su proyecto de vida, de acuerdo -en función de la gradualidad- a su capacidad de asentir, de consentir o de decidir con asistencia. En el ejercicio de la autonomía moral con asistencia hay que encontrar un equilibrio (Etxeberría, 2008) entre el principio de igualdad en que se basan las relaciones de reconocimiento jurídico y el principio de protección, de forma que aquel sirva de orientación a este último y este se aplique de forma subsidiaria. Es, por tanto, una modulación del principio de igualdad que toma en consideración la diversidad funcional ${ }^{6}$, contando con apoyos que susciten el desarrollo de la persona asistida y sean formulados en interés de la misma.

d) Hay personas cuyas capacidades determinan que, bien en ciertos momentos o bien de forma más permanente, necesiten que otra per-

6 La Convención reconoce, en su Preámbulo, apartado i, la diversidad de las personas con diversidad funcional. 
sona sustituya su autonomía moral, por las dificultades que pueden tener para la autodeterminación vital. Tradicionalmente, la solución jurídica era el recurso a la incapacitación jurídica. La Convención de 2006 hace necesario el replanteamiento del sentido normativo de esta figura jurídica (Barranco y otros, 2012). En el artículo 12 de la Convención se establecen las condiciones a que debe ajustarse su aplicación: 1) es necesaria la adopción de medidas para facilitar la asistencia en la capacidad jurídica; 2) deben respetarse los derechos, la voluntad y las preferencias personales; 3 ) ha de ser proporcional y tiene que adaptarse a las circunstancias personales; 4) ha de quedar limitada al plazo más corto posible; 5) ha de ser reexaminada periódicamente por una autoridad o por un órgano judicial competente, y 6) también se apela, en el artículo 12.3, a la adopción de medidas para garantizar la ciudadanía económica necesaria en la autonomía individual. En conjunto, el nuevo sentido normativo que adquiere la incapacitación jurídica se encamina a que las medidas impuestas bajo el principio de protección de la persona no vayan en detrimento -en esas circunstancias excepcionales que tiene- del principio de igualdad. Tiene que entenderse, por tanto, desde el paso del modelo de sustitución al modelo de apoyo en la toma de decisiones (Palacios, 2008). La sustitución se contempla, por tanto, como el caso límite de la asistencia. Cuando se requiera recurrir a este límite -de forma individualizada y no a todo un colectivo-, será necesaria la actuación, acorde con las condiciones antes indicadas, de un representante -legal o de facto. Dicha representatividad debe realizarse con respeto moral a la persona representada. Este respeto debe concretarse considerando los valores que haya tenido a lo largo de su biografía, considerando su contexto social y realizando una interpretación de sus circunstancias que sea favorable a sus intereses.

La Convención tiene en cuenta un conjunto de derechos civiles para garantizar la igual protección de la autonomía privada. Algunos de tales derechos son: no discriminación (art. 5); no discriminación de la mujer con diversidad funcional (art. 6); protección de niños y niñas con diversidad funcional (art. 7); derecho a la vida (art. 10); derecho al reconocimiento de su personalidad jurídica (art. 12); acceso a la justicia (art. 13); derecho a la libertad y la seguridad (art. 14); protección contra la tortura (art.15); protección contra la explotación, la violencia y el abuso (art.16); protección de la integridad personal (art. 17); libertad de desplazamiento y nacionali- 
dad (art.18); derecho a la vida independiente y la inclusión social (art. 19); movilidad personal (art 20), derecho a fundar una familia y a la crianza de los hijos (art. 23).

En lo que respecta a los derechos políticos de participación, el artículo 29 de la Convención garantiza a la persona con diversidad funcional la participación en la vida política y pública, en igualdad de condiciones. Este artículo garantiza: el derecho al voto ${ }^{7}$, directamente o con asistencia; el derecho a ser elegido; la accesibilidad y facilidad para entender el material electoral. También trata de fomentar la participación de la persona con diversidad funcional en asuntos públicos, en organizaciones y ONGs, en partidos políticos, así como en organizaciones que la representen. En el caso concreto de las personas con diversidad funcional intelectual, este ejercicio de la autonomía pública habrá de ser -de acuerdo a las circunstancias de cada persona- directa, con asistencia o por medio de representante -en este último caso, la participación en la vida pública tendrá que darse en procedimientos deliberativos, aunque se torna problemática en el derecho al voto.

\subsection{El reconocimiento de los derechos sociales}

Honneth lleva a cabo una doble aproximación a los derechos sociales: histórica y conceptual. Por un lado, recurre a la reconstrucción histórica del derecho moderno efectuada por T. H. Marshall, con la finalidad de explicar el origen de los derechos sociales. Dicho origen se remonta a las luchas sociales iniciadas ya en el siglo XIX, que culminarán en el siglo xx con la instauración, en la sociedad occidental, del estado de bienestar. En este se produce el reconocimiento de la nueva categoría de derechos. Las luchas sociales impulsadas por la clase trabajadora durante estos siglos respondían a la exigencia de recibir un trato jurídico igual en orden a la consecución de la plena pertenencia como ciudadanos en el seno de la comunidad política (Honneth, 1997). Estas luchas sociales estaban dirigidas a la redistribución de los recursos materiales, por lo que la ampliación producida con el reconocimiento de este tipo de derechos obedece al enriquecimiento en con-

7 En nuestro país se ha señalado lo inadecuado de la existencia de un impedimento general para poder ejercer el derecho al voto por parte de personas con diversidad intelectual. Este impedimento es contrario a lo señalado en la Convención en, al menos, dos aspectos: 1) La Convención demanda la protección de la participación de todas las personas con diversidad funcional en la vida política y, en concreto la participación en las elecciones y 2) La incapacitación no debe ser general, para todo el colectivo, sino que, en todo caso, ha de ser individualizada. 
tenidos materiales del derecho. Por otra parte, Honneth establece, en su reconstrucción normativa de la moderna relación de reconocimiento jurídico, una conexión conceptual entre los derechos sociales y el ejercicio, garantizado por el estado, de la autonomía privada:

\begin{abstract}
El sentido normativo de estos derechos sociales surge de la tarea de posibilitarle materialmente al individuo practicar con eficacia la autonomía privada afianzada en los derechos liberales [...] En este sentido, los derechos liberales de la libertad remiten conceptualmente a una complementación con derechos sociales que les garantizan a los individuos la medida de seguridad económica y bienestar material que es necesaria para explorar de manera privada, retrayéndose de los contextos de cooperación social, los propios objetivos de vida (Honneth, 2014: 109).
\end{abstract}

El mecanismo de universalización propio del derecho moderno explica la extensión progresiva de estos logros.Ahora se protege (Fraser y Honneth, 2006), hasta un determinado umbral, negociado políticamente, con iguales derechos sociales a grupos sociales excluidos o desfavorecidos, garantizando así el acceso a unos bienes esenciales mínimos.

La Convención de 2006 incluye un conjunto de derechos sociales reconocidos a las personas con diversidad funcional: a) el artículo 3 reconoce el derecho a la no discriminación y el derecho a la igualdad de oportunidades; b) el artículo 5 reconoce la igualdad ante ley y los ajustes razonables, lo que repercute en los demás derechos sociales; c) el artículo 19 reconoce el derecho a la vida independiente y a la inclusión en la comunidad, lo que supone el derecho a disponer de los servicios de asistencia domiciliaria, de los servicios a la comunidad o de la asistencia personal; d) el artículo 24 se refiere al derecho a un sistema de educación inclusivo, incorporando al mismo la accesibilidad, los apoyos razonables y las medidas de apoyo personalizadas; e) el artículo 25 reconoce el derecho a la salud, lo que se concreta en el diseño de servicios de salud que asuman las especificidades de las personas con diversidad funcional, la formación de profesionales para que presten una atención con la misma calidad que a otras personas y que sea respetuosa con la dignidad y los derechos humanos; f) el artículo 26 reconoce el derecho a la habilitación y rehabilitación en distintos ámbitos -salud, educación, empleo y servicios sociales-, y g) el artículo 27 reconoce el derecho al trabajo y el empleo en entornos inclusivos y accesibles. El conjunto de estos derechos estaría orientado, de acuerdo con Honneth, al ejercicio de la autonomía privada. Esta, a su vez, depende del ejercicio de la autonomía pública -directamente, con asistencia o por medio de representante- necesaria para que las personas con diversidad funcional ejerzan 
una ciudadanía activa, presupuesto indispensable para la concreción social de los mismos.

4.3. E1 reconocimiento de iguales condiciones de acceso a los derechos humanos: la accesibilidad universal

Otro de los aspectos más relevantes incluidos en la Convención de 2006 ha sido la cuestión de la accesibilidad (Bariffi y otros, 2008; De Asís, 2013). El diseño y la puesta en práctica de la propia vida, en las múltiples facetas que conlleva, necesita -en toda persona- del apoyo del espacio social en que esta se desarrolla. El desenvolvimiento del plan de vida personal depende, por tanto, del diseño existente en el espacio social. Ese espacio cuenta con un entorno material -vías públicas, edificios, medios de transporte, comunicaciones, etc.- y con componentes inmateriales -ideas, valores, actitudes, etc. A su vez, los valores predominantes en la sociedad tienen una influencia decisiva en la configuración que adopta el entorno social. La repercusión que tiene el diseño del entorno social, realizado desde los valores vigentes, en el plan de vida de cada persona depende de las condiciones que este diseño proporciona a quienes se desenvuelven en él. Ese entorno social estaba tradicionalmente diseñado sin atender a la inclusión, considerando las necesidades típicas de los ciudadanos «normales»e ignorando las necesidades atípicas (Nussbaum, 2007). Mientras a la mayoría de ciudadanos se les proporcionaba condiciones adecuadas de acceso al entorno social, los ciudadanos con necesidades atípicas carecían de ellas. Las diferencias en las condiciones proporcionadas para el acceso al entorno social son la clave de la exclusión de la minoría, lo que afecta a la autonomía personal para el despliegue de la vida proyectada. En ese sentido, en el art. 9 de la Convención de 2006 se justifica la introducción de medidas de accesibilidad apelando a la igualdad de condiciones que las personas con diversidad funcional han de tener con los demás ciudadanos. Se trata de cambiar las ideas y los valores vigentes en la sociedad y de hacer un nuevo diseño del entorno social, que proporcione a cada uno las condiciones de acceso adecuadas. Se trata, pues, de poner fin, progresiva y continuadamente, a una situación de discriminación histórica, en la que no se atendía por igual a las características corporales de todos los ciudadanos. Dicha excepcionalidad discriminatoria es contraria al principio de igualdad. Más allá de una igualdad uniformadora, el principio de igualdad reflejado en la Convención absorbe en su seno tales diferencias fácticas: obliga a propor- 
cionar a todos iguales condiciones de acceso como medio para garantizar una equitativa igualdad de oportunidades para que todos los ciudadanos puedan participar en la vida social. Todo ello con la finalidad de facilitar el ejercicio de la autonomía privada y pública. Se proyecta así, por decirlo con Habermas, un universalismo no nivelador, un universalismo abierto a la diferencia (Habermas, 2008b). Este universalismo responde, como Honneth pone de manifiesto, a las luchas por el reconocimiento. En tales luchas morales que demandan igual accesibilidad encontramos una mezcla de factores jurídicos, de factores económicos y de factores culturales.

Se entiende por accesibilidad universal (De Asís, 2013) la eliminación de todo tipo de obstáculo -físico, ambiental, cultural, psicológico o cognitivo- que impida o dificulte a la persona el acceso a algún ámbito de la vida social. Los diferentes ámbitos de accesibilidad (Bariffi y otros, 2008) son los relativos a:

a) La movilidad en el entorno material: diseño urbano, edificación pública o privada, uso de transportes públicos o privados, diseños tecnológicos etc. Tiene relación, por ejemplo, con el derecho al libre desplazamiento, a la educación, al trabajo, a la cultura, al ocio, etc.

b) La comunicación y la información: acceso general a medios de comunicación, el uso de lenguajes alternativos en la comunicación, el acceso a las nuevas tecnologías de la información y la comunicación, el acceso a la información, etc. Las relaciones interpersonales, el derecho a recibir información, el acceso a la educación o a la cultura, etc., están implicados en este ámbito.

c) Los bienes y servicios: bienes y servicios generados por la sociedad: educación, sanidad, servicios sociales, servicios de ocio y turismo, etc.

d) Valores $y$ actitudes: eliminación de prejuicios, apoyo a la inclusividad. etc.

El sentido normativo de la accesibilidad universal responde, a nuestro juicio, a un doble sentido: por un lado, ha de abarcar -con mínimos decentes y de acuerdo con las técnicas disponibles en cada momento- al conjunto de los ciudadanos, con independencia de sus características; por otro, ha de extenderse al conjunto de dimensiones de la ciudadanía. Lo que está en juego con la cuestión de la accesibilidad universal es su contribución al ejercicio del conjunto de los derechos humanos de la persona, así como el acceso al disfrute de los bienes y servicios producidos socialmente, deriva- 
dos de tales derechos. Ha de ser contemplada, en un sentido amplio, desde el punto de vista de su incorporación a cada uno de los derechos que tiene la persona. El objetivo que tiene proporcionar iguales condiciones de acceso es conseguir que los ciudadanos puedan tener iguales oportunidades de disfrute de los derechos, construyendo así una ciudadanía incluyente. En consecuencia, teniendo en cuenta -de acuerdo con Honneth- el sentido normativo que tiene el ejercicio de los diferentes tipos de derechos, podría decirse que el sentido normativo de la accesibilidad universal hace referencia, en último término, a la consecución, de acuerdo con el principio universalista de igualdad, de una efectiva autonomía personal.

\section{EL FUNDAMENTO DE LOS DERECHOS HUMANOS DE LAS PERSONAS CON DIVERSIDAD FUNCIONAL}

Aunque la teoría del reconocimiento de Honneth permite efectuar un diagnóstico y una evaluación del estado de la justicia social, presenta limitaciones en cuanto a la justificación de las demandas de justicia (Forst, 2014). En tal sentido, para la justificación de las demandas de justicia reflejadas en la Convención de 2006 recurrimos a la ética del diálogo.

El discurso moral-jurídico desplegado en la Convención de 2006 contiene una apelación expresa a la dignidad humana. Su objetivo destacado es la promoción del respeto moral a la dignidad de todas las personas con diversidad funcional -con independencia de las condiciones fácticas de su existencia. Dicha promoción queda conectada al reconocimiento de iguales derechos humanos $y$ al aseguramiento de iguales condiciones de acceso a los mismos.

A nuestro juicio, este documento jurídico internacional puede ser entendido, más que como sustituto de la Declaración Universal de los Derechos Humanos de 1948, como un complemento de la misma, en tanto que cualquier miembro de la humanidad está abierto a la vulnerabilidad corporal en alguna de sus fases vitales (MacIntyre, 2001; Nussbaum, 2007). Se trata de un documento en el que se refleja, por primera vez a lo largo del devenir histórico, la "conciencia mundial de lo que es justo, de qué es lo que corresponde a cada persona por el hecho de serlo» (Cortina, 2010: 99). Conciencia mundial impulsada por las luchas por el reconocimiento emprendidas por el movimiento social de personas con diversidad funcional y quienes les apoyan, que sitúa a la humanidad ante la responsabilidad para evitar el sufrimiento social al que fueron sometidas tales personas a 
lo largo de la historia y que continúa, en múltiples manifestaciones, en el mundo actual.

En el vigoroso universalismo moral-político subyacente a esta Convención no late únicamente el objetivo -irrenunciable ya desde este punto de la historia- de la inclusión del colectivo concreto de personas con diversidad funcional en el nosotros de la comunidad moral y política humana. Podría decirse que, en un sentido aún más profundo, el documento constituye un recordatorio, que debe ser incorporado también en el orden constitucional interno, de la tarea moral y política que comporta enfrentar, como señala Ricoeur, la paradoja de la autonomía y de la vulnerabilidad que atraviesa la condición humana:

Es el mismo ser humano el que es lo uno y lo otro bajo dos puntos de vista diferentes.Y es más, no contentos con oponerse, los dos términos se componen entre sí: la autonomía es la de un ser frágil, vulnerable.Y la fragilidad no sería más que una patología, si no fuera la fragilidad de un ser llamado a llegar a ser autónomo, porque lo es desde siempre en cierta manera (Ricoeur, 2008: 71).

En el documento de la Convención, elaborado con la participación de los colectivos de personas afectadas a lo largo de numerosas sesiones de debate, se recoge el consenso fáctico, alcanzado por representantes de distintas culturas en el momento histórico en que nos encontramos, a la vez que se anticipa el consenso ideal de todos los afectados en la solución justa de esta problemática. ${ }^{8}$ Desde la ética del discurso de Apel, la validez de los derechos humanos y de las correspondientes condiciones de acceso que recoge dicho documento resulta dependiente de la fundamentación filosófica. En virtud del fundamento filosófico de su validez puede decirse que «los derechos humanos no son solo un resultado contingente de la historia, sino un progreso de la historia» (Morales, 2001: 139). Apel considera que, en relación a su posible fundamento último desde la pragmática trascendental, los derechos humanos pertenecen a las «condiciones de posibilidad para el discurso argumentativo» (Morales, 2001: 137). Por su parte, Cortina lleva a cabo una fundamentación de los derechos humanos aplicando el método de la reconstrucción pragmático-trascendental de los presupuestos de la argumentación sobre la justicia de las normas. En esta reconstruc-

8 «El que argumenta no puede negar -so pena de incurrir en autocontradicción performativa- que la validez de las reclamaciones morales que plantea su interlocutor en el discurso, así como la validez de sus pretensiones de verdad, presuponen la capacidad de consenso de todos los miembros de una comunidad de comunicación idealmente ilimitada. Lo dicho es, por supuesto, aplicable también a cuantos participan en el discurso [...] sobre la fundamentación moral y la codificación jurídica de los derechos humanos» (Apel, 1998: 32). 
ción tiene en cuenta no solo la dimensión pragmático-formal de tales presupuestos, sino también la capacidad de estimar valores, de sentir y poseer virtudes. La ética cordial va más allá de la ética del discurso ya que esta solo ofrece la fundamentación de derechos pragmáticos de los interlocutores que están afectados por discursos sobre lo justo, sin que alcance a realizar una fundamentación de los derechos humanos.

Cualquier ser dotado de competencia comunicativa (Cortina, 2010) es un participante -real o virtual- en discursos prácticos en los que se establecen normas que le afectan. Para que tales discursos tengan sentido y validez, hay que presuponer los derechos pragmáticos -cuestionar cualquier afirmación, introducir cualquier afirmación, etc.- de todos aquellos que se encuentran afectados por las decisiones tomadas en ellos. Cortina entiende que, a su vez, estos derechos pragmáticos descubren otro tipo de derechos, sin cuya protección sería imposible la protección de tales derechos pragmáticos. Entre esos derechos sitúa los siguientes: a) el derecho a la vida de los seres dotados de competencia comunicativa que puedan ser afectados por las decisiones de los discursos; b) las libertades básicas -de expresión, de información, de opinión, de asociación, etc.- sin las que los interlocutores actuales o virtuales no podrían ejercer el derecho a participar sin coacción en tales discursos; c) el derecho a unas condiciones materiales y culturales, que permitan a los afectados discutir y decidir en pie de igualdad. Entiende que cabe denominar al conjunto de tales derechos como «derechos humanos», en tanto que constituyen las condiciones de posibilidad para el ejercicio de la competencia comunicativa, que solo puede ser ejercida por los seres humanos. Retomando lo indicado sobre la Convención de 2006, cabría incluir en el citado listado las iguales condiciones de acceso al conjunto de los derechos allí indicadas, en la medida en que, dada la vulnerabilidad propia de la condición corporal humana, las formas de accesibilidad a todo el listado de derechos humanos también constituyen condiciones de posibilidad para el ejercicio -actual o potencial- de la competencia comunicativa; sin ellas, algunos interlocutores no podrían participar de forma efectiva en los diálogos acerca de normas que -como la citada Convención- les afectan. Por eso mismo, como apunta Cortina, un consenso fáctico que decidiera violar algunos de tales derechos -los impidiese o retrocediese en la realización de iguales formas de accesibilidad a los mismos- atentaría también contra los presupuestos mismos del procedimiento que se ha usado para establecer tal consenso, por lo cual sería injusta y se produciría una contradicción performativa-práctica. Desde ese punto de vista, atentar contra los presupuestos que dan sentido 
a los discursos, entre los cuales cabe situar lo reflejado en la Convención de 2006, supone una contradicción performativa en el ámbito práctico, y es una decisión injusta y contraria a la racionalidad. Por eso mismo, los derechos humanos recogidos en la Convención tendrían validez y, además de ser presupuestos, tendrían que ir concretándose históricamente. De este modo, a juicio de Cortina, trascendentalidad e historia quedarían unidos como dos lados constitutivos de lo que es justo. Estos derechos, que se concretan históricamente y que tienen validez para una razón comunicativo-cordial, concretan aquello de lo que son dignos los seres humanos. Tales derechos no son otorgados por la comunidad política sino que se descubren en el reconocimiento mutuo.

Para finalizar, cabe señalar que si la justicia tiene su fundamento éticopolítico en el reconocimiento de la igual dignidad de toda persona y tal dignidad remite al conjunto de derechos humanos, entonces puede decirse que el cumplimiento efectivo de los derechos humanos incluidos en la Convención de 2006 constituye la piedra de toque del respeto a la dignidad y del trato justo debido a toda persona con diversidad funcional.

\section{BIBLIOGRAFÍA}

Abberley, P. (2008): «El concepto de opresión y el desarrollo de una teoría social de la discapacidad» en BARTON, L. (comp.) (2008): Superar las barreras de la discapacidad, Madrid, Morata.

Apel, K. O. (1998): «El problema del multiculturalismo desde la perspectiva de la ética del discurso» en CaLo, J. R. (ed.) (1998): Topografías del mundo contemporáneo, Madrid, Fundación Argentaria/Ediciones Encuentro.

BARIFFI y otros (2008): La accesibilidad universal en los medios audiovisuales de comunicación, Madrid, Real Patronato sobre Discapacidad.

BARNES, C. (2008): «La diferencia producida en una década: reflexiones sobre la investigación emancipadora en discapacidad» en BARTON, L. (comp.) (2008): Superar las barreras de la discapacidad, Madrid, Morata.

Barranco, M. C., y otros (2012): "Capacidad jurídica y discapacidad: el artículo 12 de la Convención de derechos de las personas con discapacidad», Anuario Facultad de Derecho, Universidad de Alcalá V, pp. 53-80.

BARTON, L. (comp.) (2008): Superar las barreras de la discapacidad, Madrid, Morata. 
Canimas, J. (2015): «¿Discapacidad o diversidad funcional?», Siglo Cero, 46 (2), $\mathrm{n}^{\circ}$ 254, abril-junio, pp. 79-97. [htpp://dx.doi.org/10.14201/scero20154627997]

Cortina, A. (2007): Ética de la razón cordial, Oviedo, Ediciones Nobel. -(2010): Justicia cordial, Madrid, Trotta.

De Asís, R. (2013): «Sobre la accesibilidad universal», Conferencia internacional 2008-2013, Madrid, Instituto de Derechos Humanos Bartolomé de las Casas, Universidad Carlos III.

EtXeberRia, X. (2008): La condición de ciudadanía de las personas con discapacidad intelectual, Bilbao, Universidad de Deusto.

Forst, R. (2014): Justificación y crítica. Perspectivas de una teoría crítica de la política, Madrid, Katz.

Fraser, N. y Honneth, A. (2006): ¿Redistribución o reconocimiento? Un debate político-filosófico, Madrid, Morata.

Habermas, J. (2008a): Facticidad y validez, Madrid, Trotta.

- (2008b): La inclusión del otro, Barcelona, Paidós.

Honneth, A. (1997): La lucha por el reconocimiento. Por una gramática moral de los conflictos sociales, Barcelona, Crítica.

- (2014): El derecho de la libertad. Esbozo de una eticidad democrática, Madrid, Katz.

Macintyre, A. (2001): Animales racionales y dependientes, Barcelona, Paidós.

Morales, P. (2001): «El fundamento filosófico de los derechos humanos. Karl Otto Apel entrevistado por Patricia Morales» en Morales, P. (coord.) (2001): Pueblos indigenas, derechos bumanos, e interdependencia global, México, Siglo xxi.

Nussbaum, M. C. (2007): Las fronteras de la justicia, Barcelona, Paidós.

Palacios,A. (2008): El modelo social de la discapacidad: orígenes, caracterización y plasmación en la Convención Internacional sobre los Derechos de las Personas con Discapacidad, Madrid, Ediciones Cinca.

Palacios, A. y Romañach, J. (2006): El modelo de la diversidad. La bioética y los derechos humanos como berramienta para alcanzar la plena dignidad en la diversidad funcional, Madrid, Diversitas.

Ricoeur, P. (2008): Lo justo 2, Madrid, Trotta.

Seonne,J.A. (2011): «¿Qué es una persona con discapacidad?», Ágora.Papeles de Filosofía, 30/1, pp. 143-161. 